\title{
HUBUNGAN PERAN KELUARGA DENGAN KEBERHASILAN TOILET TRAINING PADA ANAK USIA PRASEKOLAH DI LINGKUNGAN 14 KELURAHAN KARANG BEROMBAK KECAMATAN MEDAN BARAT TAHUN 2019
}

\author{
Veronica Anggreni Damanik ${ }^{1}$, Sri Lasmawanti ${ }^{2}$ \\ ${ }^{1}$ Akademi Keperawatan Helvetia Medan; ${ }^{2}$ Akademi Keperawatan HelvetiaMedan \\ Email: veronica.damanik88@gmail.com
}

\begin{abstract}
Toilet training in children is an attempt to train children to be able to control in the urine and defecate. According to data in Indonesia the number of toddlers reaches 250 million people. The number of children under five who are difficult to control chapter and $B A K$ at preschool age reaches 75 million children. The purpose of this research is to know the relation of family role to the success of toilet taining at preschool age children in Neighborhood 14 KarangBeromakSubdistrict, West Medan Sub-District Year 2019. This research used analytic survey research design with cross sectional approach. The population in this study was all families who have preschool children who numbered 32 people and the sample in this study used the total population of 32 respondents. Data analysis used univariate analysis and bivariate analysis with chi-square test. Based on the result of 32 respondents $6(18,8 \%)$ family role less 5 (15,6\%) unsuccessful and 1 $(3,1 \%)$ that succeed. While 26 out of 26 (81,3\%) good family roles $6(18,8 \%)$ unsuccessful and 20 (62,5\%) succeed. After chi-square test $p$ value $(0,011)<\alpha(0,05)$. The conclusion of this research is the relation of family role to the success of toilet training in preschool children in Environment 14 KarangBerombak Village, West Medan District. It is advisable to mothers with children of ages to teach children to do toilet training with affection and sympathy, always advise well and support and give praise for its success, avoid violence and anger.
\end{abstract}

Keywords: Family role, successful toilet training

PENDAHULUAN

Peran keluarga merupakan serangkaian perilaku yang diharapkan seseorang sesuai dengan posisi sosial yang diberikan baik secara formal dan informal. Anak mengalami banyak perubahan baik fisik dan mental pada usia prasekolah 3-5 tahun dengan karakteristik perkembangan konsep diri, rasa ingin tahu, imajinasi, belajar menimbang rasa, berkembangnya cara berpikir, berkembangnya kemampuan berbahasa dan munculnya perilaku. Pada masa ini orang tua harus sabar dan mengerti kesiapan anak untuk memulai pengajaran penggunaan toilet dan memberikan dukungan yang positif.(1)

Toilet training pada anak merupakan usaha untuk melatih anak agar mampu mengontrol dalam melakukan buang air kecil dan buang air besar. Hal ini dapat dicapai dengan selalu memberikan contoh yang baik.Toilet training juga dapat menjadi awal terbentuknya kemandirian anak secara nyata sebab anak sudah bisa untuk melakukan hal- 
hal yang kecil seperti buang air kecil dan buang air besar. (2)

Menurut data surveilans World Health Organization (WHO) mencapai $8,1 \%$ balita mengalami gangguan perkembangan dan $1,92 \%$ anak usia sekolah menyandang retardasi mental bahwa $16 \%$ mengalami gangguan perkembangan, baik perkembangan motorik halus dan kasar, sosial kemandirian, kecerdasan kurang dan keterlambatan.(2)

Hasil laporan di Negara Singapura dalam Lestari (2015) yang telah dilakukan yaitu $15 \%$ anak tetap mengompol setelah berusia 5 tahun dan sekitar $1,3 \%$ anak laki-laki serta $0,3 \%$ anak perempuan. Di Inggris masih memiliki kebiasaan $\mathrm{BAB}$ sembarangan pada usia 7 tahun, namun saat ini orang tua kurang berperan aktif dan kurang mengerti kesiapan anak, karena beberapa orang tua yang mempunyai kesibukan dengan pekerjaan mereka atau malas dalam mengantar anak ke toilet. (3)

Menurut data di Indonesia diperkirakan jumlah balita mencapai 250 Juta jiwa. Menurut Suvey kesehatan rumah tangga (SKRT) nasional diperkirakan jumlah balita yang susah mengontrol $\mathrm{BAB}$ dan $\mathrm{BAK}$ di usia prasekolah mencapai 75 Juta anak. (4)

Berdasarkan hasil penelitian Umami (2011) data yang diperoleh jumlah balita di Jawa Tengah pada bulan Oktober 2011 Desa Tunggak Kecamatan Toroh Kabupaten Grobongan balita usia antara 2-5 tahun terdapat 457 balita, dan Dusun Kernekan jumlah balita usia 1-5 tahun 106 anak, balita usia 3-5 tahun 60 anak dan balita usia 4-5 tahun 42 anak, yang telah di lakukan dengan mewawancari 10 orang tua yang mempunyai anak balita usia 4-5 tahun, didapatkan bahwa 2 orang tua memiliki pola asuh otoriter dengan toilet training 1 orang berhasil dan 1 orang tidak berhasil. (2)

Berdasarkan data yang diperoleh dari bagian kesehatan ibu dan anak Dinas Kesehatan Kota Padang pada Tahun 2016, belum ada data spesifik mengompol pada anak di Sumatera Barat khususnya Kota Padang, akan tetapi dari hasil penelitian yang dilakukan di TK Pertiwi V dan PAUD Cempaka Putih Padang, menunjukkan terdapatnya kejadian mengompol pada anak usia 5-6 tahun di Kota Padang yaitu 42,2 \% anak diantaranya masih mengompol. (5)

Pada tahun 2010 di Sumatera Utara Berdasarkan hasil penelitian di TK ALAzhar Medan yang bertujuan untuk mengetahui Gambaran pengetahuan ibu tentang toilet training pada anak usia prasekolah melalui analisis pada 58 responden mengenai gambaran pengetahuan, didapatkan hasil yaitu tingkat pengetahuan terbanyak adalah pengetahuan baik yaitu $35 \quad(60,3 \%)$ 
orang, diikuti dengan tingkat pengetahuan cukup yaitu sebanyak 22 (38\%) orang dan tingkat pengetahuan buruk yaitu $1(1,7 \%)$ orang $(6)$

Peran keluarga merupakan salah satu tugas keluarga terhadap pertumbuhan dan perkembangan anak dalam kemandirian. Orang tua lebih memakai cara praktis dengan pemakaian diapers sehingga orang tua tidak memiliki kesulitan pada saat anak mau buang air besar atau kecil, orang tua yang memiliki kesibukan juga tidak memperhatikan lingkungan di rumahnya yang tampak kotor, sehingga anak kurang nyaman dengan fasilitas untuk $\mathrm{BAB}$ dan BAK serta orang tua yang tidak memberikan fasilitas kamar mandi yang mudah dicapai oleh anak.(7)

Masalah yang ditimbulkan dari peran keluarga dalam kejadian ini adalah banyak anak usia prasekolah yang mengompol, BAB dan BAK di sembarang tempat bahkan sampai usia sekolah disebabkan karena kegagalan toilet training. Hal ini akan berdampak buruk untuk perkembangan anak ke depannya. Dampak yang ditimbulkan akibat orang tua yang tidak menerapkan toilet training pada anak di antaranya adalah anak menjadi keras kepala dan susah diatur. (7)

Peran orang tua terhadap toilet training pada anak dapat diwujudkan dalam bentuk peran antara lain seperti perhatian, bantuan instrumental, pemberian informasi dan peran penilaian pada anak dalam melakukan toilet training. Pengaruh orang tua terhadap anak dapat berdampak positif seperti menggambarkan keeratan hubungan antara orang tua dengan anak membantu mempercepat proses pemahaman dan motivasi anak dalam melakukan toilet training, peran yang di berikan orang tua tidak membuat anak menjadi tergantung terhadap bantuan, tetapi akan menjadikan anak lebih cepat mandiri karena yakin akan kemampuanya dan mengerti akan keberadaannya. (8)

Masalah yang dipengaruhi peran orang tua selain itu anak tidak mandiri dan masih membawa kebiasaan mengompol hingga besar bahkan masih ada yang menangis saat buang air kecil di celana karena takut dimarahin.Toilet training yang tidak diajarkan sejak dini akan membuat orang tua semakin sulit untuk mengajarkan pada anak ketika anak bertambah usianya dan hal-hal yang perlu di perhatikan dalam peran keluarga mengajari anak mengucapkan kata-kata khas yang berhubungan dengan $\mathrm{BAB}$ dan $\mathrm{BAK}$, mendorong anak melakukan rutinitas ke kamar mandi, jangan marahi anak bila gagal dalam melakukan toilet training serta sebagai peran orang tua harus mengajarkan teknik toilet training mengawasi masalah yang timbul dalam 
pelatihan toilet training dan mendukung cara melatih toilet training pada anak usia prasekolah.(6)

Berdasarkan survei awal yang dilakukan oleh peneliti di Lingkungan 14 Kelurahan Karang Berombak Kecamatan Medan Barat pada Maret 2019 ada 12 orang ibu yang mempunyai anak usia prasekolah dan 5 orang anak usia 3-5 tahun tidak dapat melakukan toilet training, hal ini disebabkan karena keluarga masih menggunakan diapers atau pempes dan dengan alasan belum mengerti cara tepat melakukan toilet training.

Berdasarkan paparan di atas, peneliti tertarik untuk melakukan penelitian tentang "Hubungan peran keluarga dengan keberhasilan toilet training pada anak usia prasekolah di Lingkungan 14 Kelurahan Karang Berombak Kecamatan Medan Barat tahun 2019”.

\section{METODE}

Desain penelitian ini adalah survei analitikdengan pendekatan cross sectional, yang bertujuan untuk mengetahui hubungan peran keluarga dengan keberhasilan toilet training pada anak usia prasekolah di Lingkungan 14 Kelurahan Karang Berombak Kecamatan Medan Barat.

Lokasi penelitian ini dilakukan di Lingkungan 14 terletak di Jalan Karya
Kelurahan Karang Berombak Kecamatan Medan Barat tahun 2019.

Waktu penelitian yang diperlukan untuk penelitian ini adalah mulai dari Januari sampai Maret 2019.

Populasi yang diambil dalam penelitian ini adalah seluruh masyarakat yang mempunyai anak usia prasekolah (3-5 tahun) di Lingkungan 14 Kelurahan Karang Berombak Kecamatan Medan Barat pada Maret 2019 yang berjumlah 32 orang.(11)

Sampel pada penelitian ini adalah Sampling jenuh yaitu semua anak usia prasekolah di Lingkungan 14 Kelurahan Karang Berombak Kecamatan Medan Barat yaitu 32 orang.(11)

Analisa univariat dengan melakukan analisis pada setiap variabel hasil penelitian dengan tujuan mengetahui distribusi frekuensi peran keluarga dan keberhasilan toilet training pada anak usia prasekolah.(12)

Analisa bivariat menggunakan perangkat lunak komputerisasi dengan uji Chi square, pada batas kemaknaan perhitungan statistik $p$ value $(0,05)$. Apabila hasil perhitungan menunjukkan nilai $\mathrm{p}<p$ value $(0,05)$ maka dikatakan $\left(\mathrm{H}_{0}\right)$ ditolak dan $\left(\mathrm{H}_{\mathrm{a}}\right)$ diterima, artinya kedua variabel secara statistik mempunyai hubungan yang signifikan, yaitu ada hubungan peran keluarga dengan keberhasilan toilet training pada anak usia prasekolah.(12) 
HASIL DAN PEMBAHASAN

Hasil

\section{Analisa Univariat}

Tabel 1.

Distribusi Frekuensi Peran Keluarga di Lingkungan 14 Kelurahan Karang Berombak Kecamatan Medan Barat Tahun 2019 (n=32)

\begin{tabular}{clrr}
\hline \multirow{2}{*}{ No } & Peran & \multicolumn{2}{c}{ Jumlah } \\
\cline { 3 - 4 } & Keluarga & \multicolumn{1}{c}{$\boldsymbol{f}$} & \multicolumn{1}{c}{18} \\
\hline 1. & Kurang & 6 & 18,8 \\
2. & Baik & 26 & 81,3 \\
\hline & Total & $\mathbf{3 2}$ & $\mathbf{1 0 0 , 0}$ \\
\hline
\end{tabular}

Berdasarkan tabel diketahui bahwa distribusi peran keluarga di Lingkungan 14 Kelurahan Karang Berombak Kecamatan Medan Barat Tahun 2019 dari 32 (100\%) responden, yang memiliki peran keluarga baik sebanyak 26 orang $(81,3 \%)$, sedangkan peran keluarga kurang sebanyak 6 orang $(18,8 \%)$.

Tabel 2.

Distribusi Frekuensi Keberhasilan Toilet Training Pada Anak Usia Prasekolah di Lingkungan 14 Kelurahan Karang Berombak Kecamatan Medan Barat Tahun 2019 $\underline{(\mathbf{n}=32)}$

\begin{tabular}{cccc}
\hline \multirow{2}{*}{ No } & \multirow{2}{*}{ Keberhasilan } & \multicolumn{2}{c}{ Jumlah } \\
\cline { 3 - 4 } & & $\boldsymbol{f}$ & $\mathbf{\%}$ \\
\hline 1. & Tidak Berhasil & 11 & 34,4 \\
2. & Berhasil & 21 & 65,6 \\
\hline & Total & $\mathbf{3 2}$ & $\mathbf{1 0 0 , 0}$ \\
\hline
\end{tabular}

Berdasarkan tabel dapat diketahui bahwa distribusi frekuensi keberhasilan toilet training pada anak usia prasekolah di Lingkungan 14 Kelurahan Karang Berombak Kecamatan Medan Barat Tahun 2019, diketahui bahwa dari 32
(100\%) responden keberhasilan toilet training pada anak usia prasekolah yang memiliki berhasil sebanyak $21(65,6 \%)$ orang, sedangkan yang tidak berhasil sebanyak $11(34,4 \%)$ orang.

\section{Analisa Bivariat}

Setelah diketahui distribusi frekuensi masing-masing variabel pada penelitian ini maka dilakukan dengan analisa bivariat untuk mengetahui peran keluarga (variabel bebas) dengan keberhasilan toilet training pada anak usia prasekolah (variabel terikat) dengan menggunakan uji Chi-Square.

Tabel 3.

Tabulasi Silang Peran Keluarga DenganKeberhasilan Toilet Training Pada Anak Usia Prasekolah di Lingkungan 14 Kelurahan Karang Berombak Kecamatan Medan Barat Tahun 2019 (n=32)

\begin{tabular}{|c|c|c|c|c|c|c|c|c|}
\hline \multirow{3}{*}{ No } & \multirow{3}{*}{$\begin{array}{l}\text { Peran } \\
\text { keluarga }\end{array}$} & \multicolumn{4}{|c|}{ Keberhasilan } & \multirow{2}{*}{\multicolumn{2}{|c|}{ Jumlah }} & \multirow{3}{*}{$\begin{array}{c}p \\
\text { value }\end{array}$} \\
\hline & & \multicolumn{2}{|c|}{$\begin{array}{c}\text { Tidak } \\
\text { Berhasil }\end{array}$} & \multicolumn{2}{|c|}{ Berhasil } & & & \\
\hline & & $f$ & $\%$ & $f$ & $\%$ & $f$ & $\%$ & \\
\hline 1 & Kurang & 5 & 15,6 & 1 & 3,1 & 6 & 18,8 & \\
\hline 2 & Baik & 6 & 18,8 & 20 & 62,5 & 26 & 81,3 & 0,011 \\
\hline & Total & 11 & 34,4 & 21 & 65,6 & 32 & 100 & \\
\hline
\end{tabular}

Berdasarkan tabel 4, tabulasi silang hubungan peran keluarga dengan keberhasilan toilet training pada anak usia prasekolah di Lingkungan 14 Kelurahan Karang Berombak Kecamatan Medan Barat Tahun 2019 di atas dari $32(100 \%)$ jumlah responden, peran keluarga kurang sebanyak 6 orang $(18,8 \%)$, yang tidak berhasil sebanyak 5 orang $(15,6 \%)$ dan yang berhasil 
sebanyak 1 orang $(3,1 \%)$. Sedangkan peran keluarga baik sebanyak 26 orang $(81,3 \%)$, yang tidak berhasil sebanyak 6 orang $(18,8 \%)$ dan yang berhasil sebanyak 20 orang $(62,5 \%)$. Hasil uji chi-square dengan tingkat kepercayaan 95\% diperoleh nilai $p 0,011<\alpha(0,05)$ maka hipotesis diterima $\left(\mathrm{H}_{0}\right.$ ditolak dan $\mathrm{H}_{\mathrm{a}}$ diterima) dan dapat disimpulkan bahwa ada hubungan peran keluarga dengan keberhasilan toilet training pada anak usia prasekolah di Lingkungan 14 Kelurahan Karang Berombak Kecamatan Medan Barat tahun 2019.

\section{Pembahasan}

Peran Keluarga

Berdasarkan hasil diketahui bahwa distribusi peran keluarga di Lingkungan 14 Kelurahan Karang Berombak Kecamatan Medan Barat tahun 2019 sebanyak 26 orang $(81,3 \%)$ yang memiliki peran keluarga baik, sedangkan peran keluarga kurang sebanyak 6 orang $(18,8 \%)$.

Hal ini sejalan dengan penelitian yang dilakukan oleh Iqbal Harizky Hidayat yang berjudul gambaran pengetahuan ibu tentang toilet training pada anak usia prasekolah/TK Al-Azhar Medan tahun 2010, hasil penelitian pada 58 responden mengenai gambaran pengetahuan di dapatkan hasil tingkat pengetahuan terbanyak adalah pengetahuan baik yaitu sebanyak 35 $(60,3 \%)$ orang diikuti dengan tingkat pengetahuan cukup yaitu sebanyak 22 (38\%) orang dan tingkat pengetahuan buruk yaitu sebanyak 1 (1,7\%) orang.(6)

Menurut asumsi peneliti bahwa peran keluarga di Lingkungan 14 Kelurahan Karang Berombak Kecamatan Medan Barat kurang dari yang diharapkan karena keluarga lebih memakai cara praktis dengan pemakaian diapers atau pempes sehingga keluarga tidak memiliki kesulitan pada saat anak mau buang air besar atau kecil, orang tua yang memiliki kesibukan juga tidak memperhatikan lingkungan di rumahnya yang tampak kotor, sehingga anak kurang nyaman dengan fasilitas untuk BAB dan BAK. Masalah yang ditimbulkan dari kejadian ini adalah banyak anak usia prasekolah yang mengompol, $\mathrm{BAB}$ dan $\mathrm{BAK}$ disembarang tempat, bahkan sampai usia sekolah disebabkan karena ketidakberhasilan toilet training.

\section{Keberhasilan Toilet Training Pada Anak Usia Prasekolah}

Berdasarkan hasil penelitian dapat diketahui bahwa dari 32 responden di Lingkungan 14 Kelurahan Karang Berombak Kecamatan Medan Barat Tahun 2019, diketahui bahwa keberhasilan toilet training pada anak usia prasekolah yang memiliki berhasil sebanyak 21 orang $(65,6 \%)$, sedangkan yang tidak berhasil sebanyak 11 orang $(34,4 \%)$. 
Hal ini sejalan dengan penelitian yang dilakukan oleh Atira Rustiyana penelitian ini berjudul hubungan motivasi dan stimulasi toilet training oleh ibu dengan keberhasilan toilet training pada anak prasekolah TK putra I Kelurahan Mariso Kota Makassar tahun 2014 hasil penelitian menunjukkan $30 \mathrm{ibu}$ melakukan toilet training dan berhasil 22 orang $(88,0 \%)$ dan tidak berhasil 3 orang (12,0\%). Sedangkan ibu melakukan stimulasi toilet training dan berhasil 23 orang $(92,0 \%)$ dan tidak berhasil 2 orang $(0,8 \%)$. Analisis data uji fisherexact hasil penelitian menunjukkan bahwa nilai $\mathrm{P}(0,041)<\alpha(0,05)$ dan nilai $\mathrm{P}$ $(0,003)<\alpha \quad(0,05)$ ada hubungan motivasi dan stimulasi toilet training oleh ibu dengan keberhasilan toilet training.(13)

Menurut asumsi peneliti yang dilakukan di Lingkungan 14 Kelurahan Karang Berombak Kecamatan Medan Barat Tahun 2019 dapat diketahui anak usia prasekolah mengalami ketidakberhasilan toilet training dikarenakan beberapa faktor yang mempengaruhi yaitu motivasi pada pemahaman keluarga mengenai pentingnya memberikan kata-kata positif disetiap perkembangan anak dan stimulasi yang dapat mempengaruhi peran keluarga terhadap anak usia prasekolah karena stimulasi merupakan cara untuk melatih anak agar mampu mengontrol $\mathrm{BAB}$ atau $\mathrm{BAK}$, masalah yang ditimbulkan dari toilet training dalam kejadian ini adalah anak usia prasekolah masih membawa kebiasaan mengompol, BAB dan BAK di sembarang tempat, anak menjadi keras kepala, susah diatur, tidak mandiri, bahkan masih ada yang menangis saat buang air kecil dan buang air besar di celana karena takut dimarahin.

\section{Hubungan Peran Keluarga Dengan Keberhasilan Toilet Training Pada Anak Usia Prasekolah}

Hasil penelitian yang dilakukan di Lingkungan 14 Kelurahan Karang Berombak Kecamatan Medan Barat Tahun 2019 dari tabel 4. tabulasi silang hubungan peran keluarga dengan keberhasilan toilet training pada anak usia prasekolah di atas dari $32(100 \%)$ jumlah responden, peran keluarga kurang sebanyak 6 orang $(18,8 \%)$, yang tidak berhasil sebanyak 5 orang $(15,6 \%)$ dan yang berhasil sebanyak 1 orang $(3,1 \%)$. Sedangkan peran keluarga baik sebanyak 26 orang $(81,3 \%)$, yang tidak berhasil sebanyak 6 orang $(18,8 \%)$ dan yang berhasil sebanyak 20 orang $(62,5 \%)$. Hasil uji chi-square dengan tingkat kepercayaan 95\% diperoleh nilai $p 0,011<\alpha(0,05)$ maka hipotesis diterima $\left(\mathrm{H}_{0}\right.$ ditolak dan $\mathrm{H}_{\mathrm{a}}$ diterima $)$ dan dapat disimpulkan bahwa ada 
hubungan peran keluarga dengan keberhasilan toilet training pada anak usia prasekolah di Lingkungan 14 Kelurahan Karang Berombak Kecamatan Medan Barat.

Pelatihan yang terlalu terlambat atau latihan saluran kemih yang tidak benar oleh orang tua juga merupakan faktor yang berkontribusi penting yang keluarga harus lakukan mendukung anak agar tidak mengompol di malam hari dan ditawarkan sentuhan khusus bahkan penghargaan bila anak tidak mengompol di tempat tidurnya, batasi untuk tidak meminum air terlalu banyak, khususnya menjelang waktu tidur minta anak untuk buang air kecil dan buang air besar lebih dahulu sebelum tidur. Ketidaksabaran, rasa tidak aman, rasa cemas dan perilaku orangtua yang kaku merupakan penghalang keberhasilan penanganan enuresis, keluarga harus melihat ke situasi dan mencari tahu penyebabnya jika anak mengalami masalah ini.(14)(15)

Hal ini sejalan dengan penelitian yang dilakukan oleh Tria Fatmawati tentang hubungan peran orang tua dengan keberhasilan toilet training pada usia toddler di Desa Tunggal Pager Kecamatan Pungging Kabupaten Mojokerto Tahun 2015 peran orang tua dalam mengajarkan toilet training menunjukkan hampir setengah orang tua kurang berperan sebanyak 48 orang

$\begin{array}{lrr}(48,1 \%) & \text { keberhasilan } & \text { dalam } \\ \text { mengajarkan } & \text { toilet } & \text { training } \\ \text { menunjukkan } & \text { hampir } & \text { setengah }\end{array}$
responden tidak berhasil melakukan toilet training sebanyak 37 orang $(48,1 \%)$. Berdasarkan hasil uji rank sperman didapatkan bahwa $p$ value sebesar 0,001 < 0,05 maka H0 ditolak atau $\mathrm{H} 1$ diterima dan nilai correlation coeficient sebesar 0,001 $<0,001$ artinya ada hubungan peran orang tua dengan keberhasilan toilet training pada usia toddler di Desa Tunggal Pager Kecamatan Pungging Kabupaten Mojokerjo menunjukkan rata-rata orang tua kurang berperan sebanyak 48 orang $(62,3 \%) .(16)$

Menurut asumsi peneliti yang di lakukan di Lingkungan 14 Kelurahan Karang Berombak Kecamatan Medan Barat Tahun 2019 anak usia prasekolah mengalami ketidakberhasilan toilet training disebabkan oleh anak yang belum siap dalam melakukan toilet training, anak masih memerlukan bantuan keluarga saat cebok sesudah buang air besar, keluarga masih ada yang kurang motivasi seperti kurang berkomunikasi langsung dengan anaknya, keluarga lebih memakai cara praktis dengan pemakaian diapers atau pempes sehingga keluarga tidak memiliki kesulitan pada saat anak mau BAB dan BAK, keluarga yang memiliki kesibukan tidak memperhatikan 
lingkungan di rumahnya yang tampak kotor, sehingga anak kurang nyaman dengan fasilitas untuk BAB dan BAK di toilet, anak masih mengompol, anak $\mathrm{BAB}$ dan BAK disembarang tempat, anak menjadi susah diatur.

\section{KESIMPULAN DAN SARAN}

\section{Kesimpulan}

1. Berdasarkan peran keluarga didapatkan bahwa dari 32 responden di Lingkungan 14 Kelurahan Karang Berombak Kecamatan Medan Tahun 2019, peran keluarga yang memiliki peran keluarga baik sebanyak 26 orang $(81,3 \%)$, sedangkan peran keluarga kurang sebanyak 6 orang $(18,8 \%)$.

2. Berdasarkan keberhasilan toilet training pada anak usia prasekolah dari 32 responden di Lingkungan 14 Kelurahan Karang Berombak Kecamatan Medan Barat Tahun 2019, didapatkan bahwa keberhasilan toilet training pada anak usia prasekolah yang memiliki berhasil sebanyak 21 orang $(65,6 \%)$, sedangkan yang tidak berhasil sebanyak 11 orang $(34,4 \%)$.

3. Hasil analisa bivariat dengan uji chisquare didapatkan $p$ value $0,011(p$ value $<0,05)$ yang artinya ada hubungan peran keluarga dengan keberhasilan toilet training pada anak usia prasekolah di Lingkungan
14 Kelurahan Karang Berombak Kecamatan Medan Barat tahun 2019.

\section{Saran}

\section{Bagi Keluarga}

Keluarga dianjurkan agar mengajari anak melakukan toilet training dengan penuh kasih sayang dan simpatik, selalu menasehati dengan baik dan mendukung serta memberi pujian atas keberhasilannya, hindari kekerasan dan kemarahan. Jika anak belum berhasil melakukan toilet training keluarga harus tetap memotivasi dan mendukung anak sampai anak berhasil.

\section{Bagi Lokasi Penelitian}

Dianjurkan kepada Petugas Lingkungan 14 Kelurahan Karang Berombak Kecamatan Medan Barat agar terus memberikan sumber informasi dan penyuluhan sehingga keluarga dapat mengerti dengan toilet training agar kebiasaan mengompol anak usia prasekolah dapat menurun.

\section{DAFTAR PUSTAKA}

1. Hidayat, A. A. (2010). Pengantar lтu keperawatan anak 1. Jakarta: Salemba Medika.

2. Umami, S. D. (2011). Hubungan Pola Asuh Orang Tua dengan Keberhasilan Toilet Traning Pada Anak Usia 4-6 Tahun Di TK Puspasari I Sidomoyo Godean Sleman DI Yogyakarta. STIKES'Aisyiyah Yogyakarta.

3. Lestari A. W. (2015). Persepsi orangtua tentang penggunaan 
brosur sebagai media parenting education di Taman Penitipan Anak As-Sakinah Sengkaling Kecamatan Dau Kabupaten Malang. Skripsi Jur Pendidik Luar Sekolah-Fakultas Ilmu Pendidik UM.

4. Mendur J. P., Rottie J, \& Bataha Y. (2018). Hubungan Peran Orang Tua Dengan Kemampuan Toilet Training Pada Anak Pra Sekolah di TK GMIM Sion Sentrum Sendagan Kawangkoan Satu. J Keperawatan, 6(1).

5. Rizki, M. (2012). Hubungan kesiapan anak dengan keberhasilan toilet training pada anak balita di paud dan Tk Bungong Seuleupoek Unsyiah Darussalam Banda Aceh Tahun 2012. ETD Unsyiah.

6. Hidayat I. H. (2010). Gambaran pengetahuan ibu tentang toilet training pada anak usia Prasekolah/TK di TK Al-Azhar Medan Tahun 2010.

7. Rahayu D. M., \& Firdaus F. (2017). Hubungan peran orang tua dengan kemampuan toilet training pada anak usia toddler di PAUD Permata Bunda RW 01 Desa Jatian Selatan 1 Sidoarjo. J Heal Sci. 2017;8(1).

8. Natalia S. (2006). Pengaruh Toilet Training Terhadap Kejadian ISK Berulang Pada Anak Perempuan Usia 1-5 Tahun. Program Pasca Sarjana Universitas Diponegoro.

9. Sumantri H. (2015). Metodologi penelitian kesehatan. Jakarta: Prenada Media.

10. Hidayat A. A. (2010). Metode penelitian keperawatan dan teknik analisis data. Jakarta: Salemba Medika;

11. Notoadmodjo S. (2010). Metodologi penelitian kesehatan. Jakarta: Rineka Cipta.

12. Dahlan M. S. (2011). Statistik untuk kedokteran dan kesehatan. Jakarta: Penerbit Salemba.

13. Rustiyana A., \& Arniyanti A. Hubungan motivasi dan stimulasi toilet training oleh ibu dengan keberhasilan toilet training pada anak pra sekolah TK Putra I Kelurahan Mariso Kota Makassar. $J$ Mitrasehat, 5 (1).

14. Widyastuti K, \& Hendarsih S. (2015). Pengaruh penyuluhan toilet traning pada orang tua terhadap kejadian enuresis di taman kanakkanak Bhakti Siwi Kalimeneng Kemiri Purworejo. STIKES' Aisyiyah Yogyakarta.

15. Padila. (2012). Buku Ajar Keperawatan Keluarga. Yogyakarta: Nuha Medika.

16. Munjiati M, Fitriyani A., \& Walin W. (2017). The Effect of Disposable Water (Diaper) Usage Toward Toilet Training Behavior In Pre-School Children. J Kesehat Masy, 13(2). 